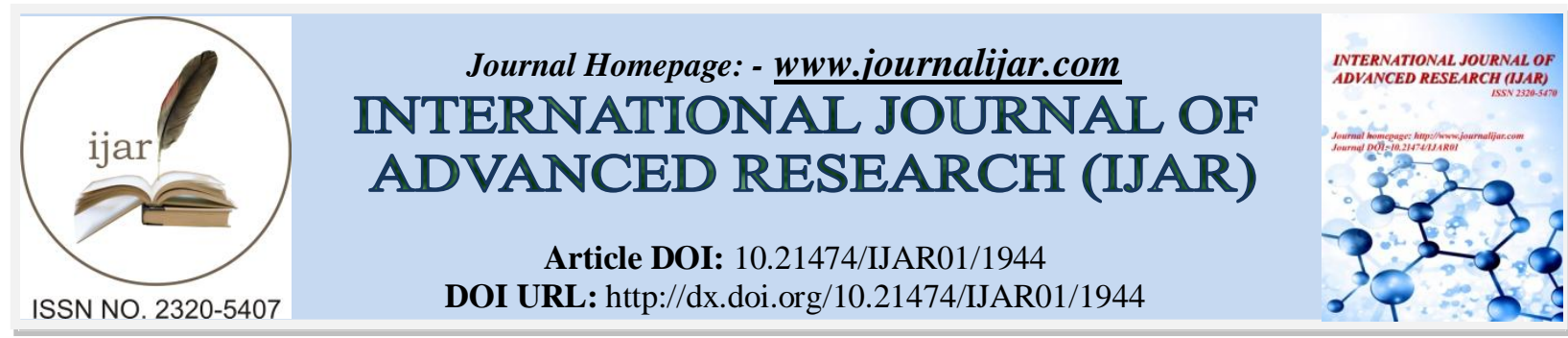

RESEARCH ARTICLE

\title{
EVALUATION OF INTERLEUKEN-6 (IL-6) IN OSTEOPOROTIC PATIENT'S BEFORE AND AFTER CALCIUM TREATMENT.
}

Dr. Waled Faris Abdulqader.

M.B.Ch.B, F.I.C.M.S, Lecturer in Department of Surgery, College of Medicine, AL-Iraqia University, Baghdad, Iraq.

\section{Manuscript Info}

Manuscript History

Received: 25 August 2016

Final Accepted: 26 September 2016

Published: October 2016

Key words:-

Osteoporosis, Interleukin, Calcium.

\section{Abstract}

Bachground:- Osteoporosis (OP) is a disease which is characterized by a low bone mass and a microarchitectural deterioration of the bone tissue, which lead to an enhanced bone fragility and a consequent increase in the fracture sites. There are two types of osteoporosis,

Type1: (post menopausal) osteoporosis is caused by an acceleration in the bone turnover as a result of hormone decrease (especially estrogen).

Type2: (senile osteoporosis) the impaired of osteoblastic activity for forming new bone, the resorption is either normal or enhanced, resulting in a chronic imbalance in the bone remodeling, leading to defects in the bone mass.

Objective:- To evaluate the role of the Interleukin-6(IL-6) in Osteoporotic patient's before and after Calcium treatment. Interleukin6 is a substance produced in response to injury or trauma of tissue by specialized white blood cells called T-cells, as well as macrophages and endothelial cells. The term interleukin derives from (inter) as a means of communication and (leukin) deriving from the fact that many of these proteins are produced by leukocytes and act on leukocytes, it has since been found that interleukins are produced by a wide variety of body cells. However, it also classified as a cytokine, meaning that it is involved in relaying information between cells as both a signaling molecule and a signaling protein. Interleukin-6 plays an important role in regulating cell growth as well as immune functioning. In fact, its release is triggered by tissue damage or infection.Interlukin-6 consider the best marker for function of Immune system. Impaired or uncontrolled interleukin-6 gene expression can produce unwanted immune responses and lead to a variety of diseases, including autoimmune disorders.

Patients and Methods :- 60 patients (20 OP cases , 20 OP cases with treatment \& 20 healthy controls) were enrolled in this study. The patients studied in this case-control study have been selected from patients attended Rheumatology and Rehabilitation Out-Patient Clinic, Al-Yarmouk Teaching Hospital during the period from November 2014 to January 2016. About five milliliters of venous blood was aspirated using disposable syringes and needles. Measurement of IL-6 
in serum: The IL-6 Enzyme immunoassay kit provides materials for the quantitative determination of IL-6 in serum and plasma.

Results: T-test was used to find out the significant of difference between two means ,this study showed significant increase of IL-6 in OP patients ( mean $\pm \mathrm{SD})(3.305 \pm 0.909)$ when compared to controls $($ mean $\pm \mathrm{SD})(1.180 \pm 0.647)$, P-value $<0.05$, in OP patients with treatment $($ mean $\pm \mathrm{SD})(2.530 \pm 0.785)$ when compared to controls ( mean \pm SD) $(1.180 \pm 0.647), \overline{\mathrm{P}}$-value $<0.05$ and in OP patients ( mean \pm SD) $(3.305 \pm 0.909)$ when compared to OP patients with treatment $($ mean $\pm \mathrm{SD})(2.530 \pm 0.785), \mathrm{P}$-value $<0.05$.

Conclusion:-Bone is formed from a complex matrix of proteins within which calcium and other minerals are deposited, The calcium and phosphate combining together in the crystalline complex; hydroxyapatite [Ca10(PO4)6 $(\mathrm{OH}) 2]$ to form the bone tissue, this complex provides the hard and rigid structure of bone which is essential to its function in supporting soft tissues and as a store of calcium for other body functions,

This study show increase in IL-6 for OP cases because the IL-6 has important role at immune function, since the OP cases occur with Osteoarthritis (OA) disease at same time for old age .After treatment by calcium there is significant decrease in IL 6 indicating that patients with osteoporosis respond well to treatment by calcium.

Copy Right, IJAR, 2016,. All rights reserved.

\section{Introduction:-}

According to the WHO, osteoporosis is a disease which is characterized by a low bone mass and a microarchitectural deterioration of the bone tissue, which lead to an enhanced bone fragility and a consequent increase in the fracture sites. There are two kinds of osteoporosis, classification into two types, based on the uncoupling defects which are seen in the remodeling unit. ${ }^{(1-3)}$

Type 1:- (post menopausal) osteoporosis is caused by an acceleration in the bone turnover as a result of hormone decrease (especially estrogen). Although the estrogen deprivation is useful to remodeling unit, the bone resorption exceeds the bone formation because of the time constraints on the osteoblastic activity, ultimately resulting in bone loss. ${ }^{(4)}$ Type 2:- (senile osteoporosis) the impaired of osteoblastic activity for forming new bone, the resorption is either normal or enhanced, resulting in a chronic imbalance in the bone remodeling, leading to defects in the bone mass, ultimately resulting in an increased susceptibility for bone fractures. Worldwide, the risk for women to have an osteoporotic fracture is $30-40 \% .^{(1)}$ In the other hand, Osteoporosis is disease with a strong genetic component, characterized by reduced bone mass and increased fracture risk. Current evidence suggests that the inheritance of bone mass is under polygenic control but the genes responsible are poorly defined.The important genes are the COLIA1 and COLIA2 that responsible to encoded of collagen proteins. ${ }^{(5)}$ Osteoporotic fractures are a cause of morbidity and mortality in the elderly population ${ }^{(6)}$. The osteoporosis fracture risk is assessed by the Bone Mineral Density (BMD), which is a measure of the bone mass and a predictor of fracture, since the bone mass affects the bone strength or the ability to withstand trauma. It has been well established that $90 \%$ of the variance in the bone strength is related to the BMD. The risk of fracture is known to be higher in women with low BMD. ${ }^{(6)}$ Osteoporosis may be predicted from the bone turn over markers and BMD, because a low BMD is associated with a high turnover. ${ }^{(1)}$ It can also be predicted independently by BMD, since an increased bone turnover negatively affects the bone microarchitecture and the fragility. ${ }^{(7)}$ The BMD measurements $(\mathrm{g} / \mathrm{cm} 2)$ for the upper end of the left femur were obtained by dual energy X- Ray absorptiometry (DXA) with the use of a lunar DPX GE medical system. The World Health Organization recently published a document in which it attempted to clarify the definition of BMD and to assist clinicians in their interpretation of the bone-densitometry results. According to that report, a normal value for the bone-mineral content was the T score more than -1. Osteopaenia was considered to be present when the T score was less than -1 and more than -2.5 . Osteoporosis was considered to be present when the T score was less than $2 . .^{(1,3)}$ 
Interleukin-6 is a substance produced in response to injury or trauma of tissue by specialized white blood cells called T-cells, as well as macrophages and endothelial cells. ${ }^{(8)}$ The term interleukin derives from (inter) as a means of communication and (leukin) deriving from the fact that many of these proteins are produced by leukocytes and act on leukocytes, it has since been found that interleukins are produced by a wide variety of body cells. However, it also classified as a cytokine, meaning that it is involved in relaying information between cells as both a signaling molecule and a signaling protein. As such, interleukin-6 may behave as both an anti-inflammatory agent and a proinflammatory mediator, depending on certain conditions. ${ }^{(9)}$ Interleukin-6 is known by many other names, including interferon-B2, cytotoxic T-cell differentiation factor, and B-cell stimulatory factor- $2{ }^{(10)}$ It is also classified as a monomer, meaning that it belongs to a group of organic compounds that can bond with similar molecules to form polymers. Specifically, interleukin-6 is a monomer of 184 amino acids secreted by these specialized cells. This release occurs at a single gene site known as $7 \mathrm{p} 21 .{ }^{(11)}$ Interleukin-6 plays an important role in regulating cell growth as well as immune functioning. In fact, its release is triggered by tissue damage or infection. Receptor sites are found on the surface of numerous cells throughout the body. From these sites, interleukin-6 transports a variety of proteins through the three major signal transduction pathways: protein kinase $\mathrm{C}$, cAMP/protein kinase A, and calcium release. Each interleukin-6 molecule performs a specific action, depending on the cell that initiated its release. ${ }^{(9)}$ The circulation of interleukin- 6 stimulates the immune system by promoting what is known as the acutephase reaction. This process encourages the production and release of acute-phase proteins, which behave as generic antibodies. In particular, the release of C-reactive protein increases phagocytosis, the process by which certain cells surround and neutralize invading bacteria and other pathogens. This results in an acute-phase response, such as fever. This is due to increased energy distribution in muscle and fatty tissue, which causes body temperature to rise. ${ }^{(1)}$ Interleukin-6 is also known as a myokine, a type of cytokine triggered by muscle contraction and then discharged into the blood stream, this exchange promotes a variety of biologic actions. For one thing, it increases the breakdown of fats. It also improves insulin resistance, resulting in better uptake and utilization of glucose. Therefore, interleukin- 6 therapy may have an application in treating certain conditions, such as obesity and diabetes type II. ${ }^{(12)}$ Interlukin-6 consider the best marker for function of Immune system. Impaired or uncontrolled interleukin-6 gene expression can produce unwanted immune responses and lead to a variety of diseases, including autoimmune disorders. Patients with rheumatoid arthritis, for example, typically have elevated levels of interleukin6 in their synovial tissue. To combat this dysfunction, researchers continue to investigate different ways to inhibit binding of interleukin-6. This includes development of an anti-interleukin-6 receptor antibody. ${ }^{(13)}$ Interleukins are group of cytokines because they regulate in formation transfer among different types of leukocytes during various stage of immune or inflammatory response secreted Proteins/signaling molecules/ that were first seen to be expressed by white blood cells (leukocytes). ${ }^{(14)}$ The function of the immune system depends in a large part on interleukins and rare deficiencies of number of them have been described, all featuring autoimmune diseases or immune deficiency, the majority of interleukins are synthesized by helper CD4+T lymphocytes as well as through monocots macrophages, and endothelial cells. They promote the development and differentia on of $\mathrm{T}, \mathrm{B}$, and hematopoietic cells. ${ }^{(15)}$ Interleukine-6 (IL-6) and other markers \{like Tumor Necrosis Factor (TNF) alpha and IL-1\} are increase with nodal OA. ${ }^{(16)}$

\section{Patients and Methods:-}

60 patients (20 OP cases, 20 OP cases with treatment \& 20 healthy controls) were enrolled in this study. The patients studied in this case-control study have been selected from patients attended Rheumatology and Rehabilitation Out-Patient Clinic, at Al-Yarmouk Teaching Hospital during the period from November 2014 to January 2016. They were randomly selected, diagnosed clinically and radiologically. Many laboratory tests have been done for each patients to exclude other possible causes of diseases, these tests were, ESR, C-reactive protein (CRP), Rheumatoid factor (RF) and serum uric acid . A pre-tested questionnaire was designed to obtain information from both patients and control group about past medical and drug history. About five milliliters of venous blood was aspirated using disposable syringes and needles. Samples were collected between 09.00-12.00 am. The blood was allowed to clot in plain tubes for 15 minutes, serum was obtained by centrifugation at $3000 \mathrm{rpm}$ for 10 minutes and transferred into plain plastic tubes and kept frozen at $20 \mathrm{C}$ untill the time of assay. Measurement of IL-6 in serum, The IL-6 Enzyme immunoassay kit provides materials for the quantitative determination of IL-6 in serum and plasma. This assay is intended for in vitro diagnostic use only. The IL-6 was measured using is a solid phase enzyme-linked immunosorbent assay (ELISA) based on the sandwich principle. ${ }^{(17)}$ 


\section{Normal values: 0.4-2.1 Pg/ml}

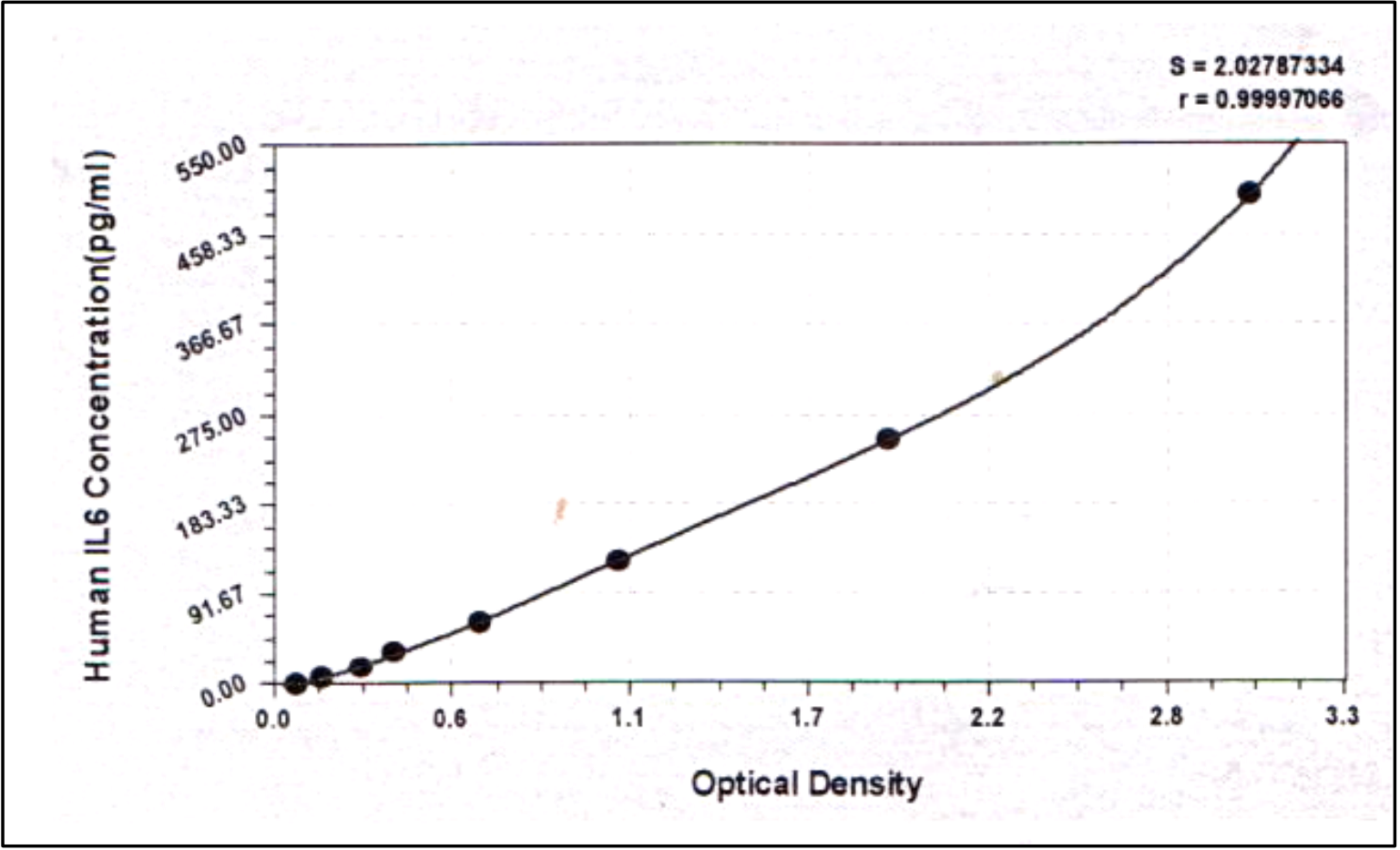

Figure 1:- Standard curve of IL-6 (pg/ml)

Cusabio - China Human IL-6 ELISA Kit was used to determine serum IL-6 level in this study for subjects:The results were presented as sample size (n), mean + standard deviation (SD) .the statistical significance of difference in mean between two groups was analyzed by student t-test. P-value $<0.05$ was considered statistically significant.

All statistical analyses were done using IBMSPSS version 21 computer software (Statistical Packages for Social Sciences).

\section{Results:-}

T-test was used to find out the significant of difference between two means, this study showed significant increase of IL-6 in OP patients ( mean \pm SD) $(3.305 \pm 0.909)$ when compared to controls ( mean \pm SD) $(1.180 \pm 0.647)$, Pvalue $<0.05$, in OP patients with treatment $($ mean $\pm \mathrm{SD})(2.530 \pm 0.785)$ when compared to controls $($ mean $\pm \mathrm{SD})$ $(1.180 \pm 0.647)$, P-value $<0.05$ and in OP patients $($ mean $\pm \mathrm{SD}) \quad(3.305 \pm 0.909)$ when compared to OP patients with treatment $($ mean $\pm \mathrm{SD})(2.530 \pm 0.785)$, P-value $<0.05$ (Table 1) .

Table 1:- Comparison of serum IL-6 between three groups ( OP patients, OP patients with treatment and controls.

\begin{tabular}{|l|l|l|l|}
\hline & $\begin{array}{l}\text { Controls }(\mathrm{n}=20) \\
\text { Mean } \pm \text { SD }\end{array}$ & $\begin{array}{l}\text { OP cases }(\mathrm{n}=20) \\
\text { Mean } \pm \text { SD }\end{array}$ & P-value \\
\hline IL-6 $(\mathrm{Pg} / \mathrm{ml})$ & $1.180 \pm 0.647$ & $3.305 \pm 0.909$ & 0.003 \\
\hline & Controls $(\mathrm{n}=20)$ & $\begin{array}{l}\text { OP with treatment }(\mathrm{n}=20) \\
\text { Mean } \pm \text { SD }\end{array}$ & \\
& Mean \pm SD & $2.530 \pm 0.785$ & 0.009 \\
\hline & $1.180 \pm 0.647$ & OP with treatment $(\mathrm{n}=20)$ & \\
\hline & OP cases $(\mathrm{n}=20)$ & Mean \pm SD & \\
& Mean $\pm \mathrm{SD}$ & $2.530 \pm 0.785$ & 0.02 \\
\hline & $3.305 \pm 0.909$ &
\end{tabular}




\section{Discussion:-}

This study show increase in IL-6 for OP cases because the IL-6 has important role at immune function , since the OP cases occur with Osteoarthritis (OA) disease at same time for old age. Through this study show that the cases have OP and OA together.There are two methods that show the relationship between (BMD) and OA, these are genetic and metabolic, because the two diseases occur at old age. ${ }^{(18)}$ The genetic method shows relationship between OA and BMD by know gene responsible for OA and decrease BMD and bone turnover.

(Tim , et al, 2004) have proved this correlation. This proved when they found urinary collagen cross links (markers of bone resorption) is due to share genes for two diseases. ${ }^{(18)}$ The metabolic method shows the relationship between BMD and OA as there is a correlation of sex hormones and turnover of bone. there are various studies about this subject, (Burger, et al,1996) showed that BMD increase for patients with general OA but after 60 years age the BMD decreases. ${ }^{(19)}$ (Valentina Živković , et al, 2010) showed that at postmenopausal period BMD was decrease. ${ }^{(20)}$. (Abir Naguib, et al, 2011) also showed that with age the bone turnover increase due to increase of urinary deoxypyridinoline (DPD) . These three studies supported the results of our study because our cases have age 60 years and more, also all the females in our study are postmenopausal..$^{(21)}$

This study shows significant increase of serum IL-6 in OP patients when compared with controls. This difference is due to that all the OP cases are postmenopausal, estrogen hormone decrease physiologically at this condition and leads to error at bone formation because Osteoclast apoptosis is regulated by estrogens . (22) With estrogen deficiency, the osteoclasts live longer and are therefore able to absorb more bone and this will promote increase IL6 level because interleukin- 6 is a potent stimulator of bone resorption, and estrogen blocks the osteoblasts synthesis of IL-6. Estrogen may also antagonize the IL-6 receptors, this lead to decrease osteocalcin then a decrease of BMD and the appearance of urinary deoxypyridinoline (DPD). ${ }^{(23)}$ This results agree with (Abir Naguib, et al, 2011) who proved that the relationship between OP ,bone turnover and urinary DPD . IL- 6 can be an important mediator in increased bone resorption of OP patient because it mediated the inflammation in joints and this results agree with (Dequeker, et al ,2003). ${ }^{(21)}$

Bone is formed from a complex matrix of proteins within which calcium and other minerals are deposited, The calcium and phosphate combining together in the crystalline complex; hydroxyapatite [Ca10( $\mathrm{PO} 4) 6(\mathrm{OH}) 2]$ to form the bone tissue, this complex provides the hard and rigid structure of bone which is essential to its function in supporting soft tissues and as a store of calcium for other body functions, calcium is essential for bone development and an adequate intake during childhood and adolescence is essential.If we loss calcium in our diet, our bones may not reach their genetic potential and peak bone mass. At menopausal changes in calcium metabolism are the cause or the result of postmenopausal bone loss. The first interpretation relies on evidence of a positive action of estrogen on the gastrointestinal absorption and renal tubular reabsorption of calcium; the latter interpretation relies on evidence of a direct inhibitory effect of estrogen on bone resorption. ${ }^{(24)}$ The calcium model for postmenopausal bone loss tends to be supported by the effect of calcium therapy, However, trials in which calcium and estrogen have been directly compared have shown that the latter is generally more effective than calcium in that it produces a small, but often significant bone gain. ${ }^{(25)}$ This superiority of estrogen over calcium could be due to the former's dual action on calcium absorption and excretion or to a direct action of estrogen on bone itself. In older women, the importance of calcium intake is overshadowed by the strong association between vitamin D insufficiency and hip fracture. ${ }^{(26)}$

Whether this insufficiency arises primarily from lack of exposure to sunlight or to a progressive failure to activate the vitamin D precursor in the skin or both is uncertain but it is compounded by a general decline in dietary vitamin $\mathrm{D}$ intake with age.The biological effect is probably an impairment of calcium absorption and consequent acceleration of bone loss . ${ }^{(27)}$ This is not to imply that all forms of osteoporosis are due to negative calcium balance. In corticosteroid osteoporosis and in age-related osteoporosis in men, depression of bone formation is probably a critical factor. Nonetheless, established osteoporosis of all kinds is so commonly associated with malabsorption of calcium and/or high obligatory calcium excretion as to suggest that negative calcium balance has at least a contributory, if not a causal role in most forms of osteoporosis. ${ }^{(28)}$ 


\section{References:-}

1. Kalaiselvi VS, Prabhu K, Mani Ramesh,et al." The Association of Serum Osteocalcin with the Bone Mineral Density in Post Menopausal Women". Jclin Diagn Reas. 2013 . 5. 814-816.

2. Moyad MA "Preventing male osteoporosis: prevalence, risk, diagnosis and imaging test " .UrolClinNAm .2004. 31.321-30.

3. National Institute for Health and Care Excellence." Osteoporosis pathway" .updated: 02 January 2014.

4. Ishii K, Taguchi A, Nakamoto T, et al . "Diagnostic efficacy of alveolar bone loss of the mandible for identifying postmenopausal women with femoral osteoporosis". Dentomaxillofac Radiol.2007.36.28-33

5. Struan F. A. Grant . "Reduced bone density and osteoporosis associated with a polymorphic Sp1 binding site in the collagen type I $\boldsymbol{\alpha} 1$ gene". Nature Genetics. 1996. 14. $203-205$.

6. Cummings SR, Black DM, Nevin MC, et al . "Bone density at various sited for prediction of hip fractures". The study of osteoporotic fractures research group Lancet . 1993. 341.72-75.

7. Seeman E and Delmas PD ." Bone quality the material and structural basis of bone strength and fragility" . N Engl J Med .2006. 354 . 2250-61.

8. Cem Gabay." Interleukin-6 and chronic inflammation". Arthritis Research \& Therapy, 2006.2. 3.

9. SIMON A. JONES, SANKICHI HORIUCHI,NICHOLAS TOPLEY, et al . "The soluble interleukin 6 receptor: mechanisms of production and implications in disease". FASEB Journal .2001.15.43-58.

10. Anne Månsson Kvarnhammar and Lars Olaf Cardell ." Pattern-recognition receptors in human eosinophils". Immunology. 2012.136. 11-20.

11. Jason Robert Sutherland. "THE ROLE OF SEMINAL PLASMA IN CERVICAL CARCINOMA". University of Cape Town Medical School.2010.46.

12. Pura Muñoz-Cánoves ,Camilla Scheele ,Bente K, et al."Interleukin-6 myokine signaling in skeletal muscle: a double-edged sword ". FEBS J. 2013. 17. 4131-48,

13. Lam J, Takeshita S, Barker JE, et al "TNF-alpha induces osteoclastogenesis by direct stimulation of macrophages exposed to permissive levels of RANK ligand" . J Clin Invest.2000 . 106 .1481 - 8 .

14. Karen M. Henkels, Kathleen Frondorf, M. Elba Gonzalez-Mejia, et al ." IL-8-induced neutrop hil chemotaxis is mediated by Janus kinase 3 (JAK3)". Edited by Beat Imhof. 2011. 1. 159-166.

15. B. H. AL-Wihaly." Evaluation Interleukin -8 and High Sensitivity C -Reactive Protein in Sera of Control Group and Human Female Patients with Osteoarthritis Nodal in Iraqi's Patients". IBN AL- HAITHAM J. FOR PURE \& APPL. SCI. 2011. 24 .3.

16. Naomi Schlesinger." The pathogenesis of bone erosions in gouty arthritis". Ann Rheum Dis. 2010. 69.19071912.

17. Guo L, Jiang F, Tang YT, et al."The Association of Serum Vascular Endothelial Growth Factor and Ferritin in Diabetic Microvascular Disease in Diabetes". technology \& therapeutics. 2014. 4.224-34 .

18. Tim D. Spector MD, Alex J and MacGregor MD. " Risk factors for osteoarthritis: genetics1 " . OsteoArthritis and Cartilage . 2004.12. 39-44.

19. Valkenburg HA, Hofman A and Grobbee DE, " Association of radiographically evident osteoarthritis with higher bone mineral density and increased bone loss with age: the Rotterdam Study". Arthritis Rheum; 1996.39:81-6.

20. Bojana Stamenković, Jovan Nedović, Aleksandar Dimić and et al." Bone Mineral Density in Osteoarthritis" . Scientific Journal of the Faculty of Medicine in Niš. 2010.27.135-141.

21. Lauren K King, Lyn March, and Ananthila Anandacoomarasamy ." Obesity \& osteoarthritis". Indian journal of medical research . 2013. 2. 185-193.

22. Bharadwaj S, Naidu AG, Betageri GV and et al . "Milk ribonuclease-enriched lactoferrin induces positive effects on bone turnover markers in postmenopausal women". Osteoporos Int .2009.20 . 1603-11 .

23. "BMI Classification". Global Database on Body Mass Index. World Health Organization . Retrieved July 27, 2012.

24. Nordin, BEC, Need, AG, Morris, HA, Horowitz, M. The nature and significance of the relation between urine sodium and urine calcium in women. J Nutr. 1993;123:1615.

25. Prince, RL, Dick, I, Devine, A et al, The effects of menopause and age in calcitropic hormones: A crosssectional study of 655 healthy women aged 35 to 90. J Bone Miner Res. 1995; 10:835.

26. Ĺopez, JM, Gonźalez, G, Reyes, V, Campino, C, Diaz, S. Bone turnover and density in healthy women during breastfeeding and after weaning. Osteoporosis Int. 1996;6:153.

27. B.E.Christopher Nordin ."Calcium and osteoporosis" .1997 .13. 664-686.

28. Klesges, RC, Ward, KD, Shelton, $\mathrm{ML}$ et al, Change in bone mineral content in male athletes. JAMA.1996;276:226. 